\title{
Life Cycle Assessment of a Biodiesel Production Unit
}

\author{
Priscilla Sieira ${ }^{1}$, Erick B. F. Galante ${ }^{1,}$, , Alvaro J. Boareto Mendes ${ }^{1}$, Assed Haddad ${ }^{2}$ \\ ${ }^{1}$ Instituto Militar de Engenharia, Department of Chemical Engineering, Rio de Janeiro, Brazil \\ ${ }^{2}$ Universidade Federal do Rio de Janeiro, Department of Civil Engineering, Rio de Janeiro, Brazil
}

\section{Email address:}

pri_sieir@hotmail.com (P. Sieira), egalante@ime.eb.br (E. B. F. Galante), boareto@ime.eb.br (A. J. B. Mendes), assed@poli.ufrj.br (A. Haddad)

\section{To cite this article:}

Priscilla Sieira, Erick B. F. Galante, Alvaro J. Boareto Mendes, Assed Haddad. Life Cycle Assessment of a Biodiesel Production Unit. American Journal of Chemical Engineering. Vol. 3, No. 2, 2015, pp. 25-29. doi: 10.11648/j.ajche.20150302.11

\begin{abstract}
Carbon dioxide is one of the main compounds pointed as a cause for climate changes, mainly due to the accelerated use of fossil fuels. In order to measure the consumption of the resources that generate carbon dioxide and verify these compounds emissions, quantitative studies aren't sufficient, but it is needed a proportion relation with the environmental impact. Hence, Life cycle analysis (LCA) studies are used to establish parameters to this relation, orientating which is the best way to be followed and also estimating, as close as possible to the reality, the degree of impacts that can be caused. In this paper a biodiesel plant LCA study is realized, using the model described in ISO 14040 groups. Biodiesel is an alternative renewable fuel to the common diesel. Despite been considered a "clean" fuel, its fabrication process involves environmental impacts. This paper quantifies those impacts, from a theoretical biodiesel plant data, and compares them with those generated on the biodiesel production. The conclusions achieved are that the carbon dioxide generated is greater than the consumed during the entire biodiesel life cycle. However, the biodiesel production generates about 174 times less carbon dioxide than the refining to obtain diesel. Besides, both diesel and biodiesel are responsible for Nitrogen oxide emissions (qualitatively) and it is possible estimate that the environmental impact generated by those emissions is similar between these fuels.
\end{abstract}

Keywords: Life Cycle Assessment, Biodiesel, Diesel, Simulation, Environmental Impact, Carbon Dioxide, Production, Global Warming

\section{Introduction}

The scarcity of fossil fuels, which was announced in the coming decades [1], and its polluting effects on the environment, has led researchers and the scientific community to search for new energy options. In this scenario, we highlight the use of cleaner and renewable resources, such as biofuels.

One of the main reasons to promote the use of biofuels, specifically ethanol and biodiesel, is the necessity to reduce emissions of greenhouse gases. Currently, much of the carbon dioxide emissions, responsible for the phenomenon mentioned, is due to use of fossil fuels [2].

Ordinary diesel is a product of petroleum refineries and is largely used in Brazil as a fuel for large vehicles. Biodiesel is a cleaner renewable alternative and is also derived from natural sources. The main advantage of the use of biodiesel is that it can be used directly in conventional engines, producing more nitrogen oxides, but in contrast, less oxides of carbon and particulate materials than diesel [3].

Brazil is a country with great potential for producing cleaner fuels, since the territory is extensive and the climate and soil are favorable. Therefore, there is an increasing interest in research on biodiesel. However, studies have shown that the generation of biofuels can cause more environmental impact than their similar fossil fuels [4].

Life cycle analysis studies are used to compilation and evaluation of the inputs, outputs and the potential environmental impacts of a product system throughout its life cycle. Given this context of environmental concern and potential of the country, it is necessary to expose quantitatively the environmental impacts in the production of biodiesel, through the LCA of this fuel and comparison to the diesel emissions. In this paper a biodiesel plant LCA study is realized, using the model described in ISO's 14040 group [5]-[7].

\section{Objectives}

The aim of this study is to analyze the environmental impacts caused by a theoretical biodiesel production plant, as 
well as compare with diesel impacts, through a simulation in the free software openLCA [8], based on the environmental indicator TRACI, in order to measure the life cycle of a biodiesel plant. The inventory data used are those from the work done by Sieira in early 2014 [9].

\section{Methodology}

The simulation was carried out using openLCA [8], software and NREL U.S. LCI database, considering the environmental indicator TRACI. Regarding the LCI - Life Cycle Inventory data, the collection was obtained from the work carried out by Sieira [9], as well as the study of environmental indicators and the choice of the most appropriate process indicator. Since there is not yet a well-established Brazilian bank data, we chose to use the NREL U.S. LCI database in this study.

\section{Environmental Indicator}

Prior to choosing any environmental indicator for the purpose of this study, some study of the indicator's characteristics was needed to choose the most suitable one for the work. For this particular study, there are 06 (six) aspects to be considered:

i. Operating conditions of the plant: The plant operates under mild conditions of pressure and temperature, i.e., the plant consumes few inputs that generate environmental impacts to maintain the process conditions and operations.

ii. Elementary streams: The plant uses water as elementary stream. Among the advantages of using water in this process we can highlight the amount of water available in the country, the low cost of it and especially its high heat capacity. These characteristics make it a low-environmental impact cause since it is needed few fuel to heat the process water. However, water used to wash biodiesel is not utilized after the biodiesel production or methanol recovery units. This wash water has toxic compounds and should be handled carefully.

iii. Soybean oil and biodiesel: Soybean oil is composed of various fatty acids and biodiesel is a mixture of esters. For this reason, their formula is not accurate and is only estimated in some databases.

iv. Soybean: For cultivation of grain, fertilizers are used. A trace of nitrogen is still present in soybean oil and biodiesel material. When biodiesel is burned, the fuel generates NOx gas.

v. Methanol reagent used is toxic and volatile.

vi. Sub-product: At the end of the process we obtain a large amount of glycerol. This glycerol is not a toxic or a polluting substance, but this entire amount has no market and it can be interpreted as something to be discarded.

Given the considerations above, the indicator of choice is TRACI. This indicator has the most current methodologies for impact assessment for the categories of interest in this study.

\section{Simulation Results}

The simulations were carried out with the data of inventories published by Sieira [9] using the OpenLCA software [8] and NREL U.S. LCI database, considering the environmental indicator TRACI.

The system studied here is part of the biodiesel life cycle, which begins with the sourcing of raw materials. Thus, each entry of the study comprises the use and emissions of elementary streams; that is, each data of the inventory is connected to other subsystems. For the purpose of this study, the inventory used is the one published by Sieira [9]. A representative schematic of this study can be seen in Figure 1.

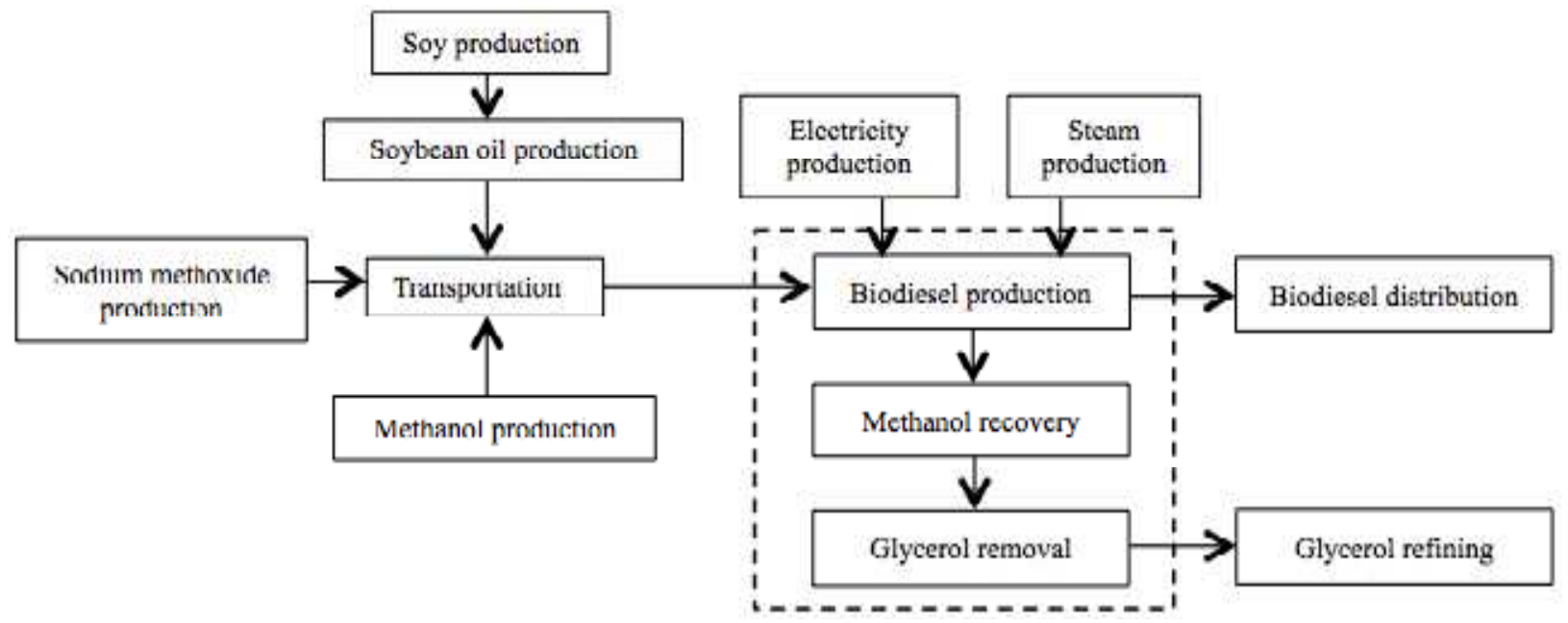

Figure 1. Production Process Schematics: Boundaries of the System Adapted from Sieira [9].

The database used provides a series of compounds, services and energy resources, all based on data collected for North America. Each of the streams is linked to several production processes, thus compounding a supply chain. The simulator allows performing an extrapolation to other subsystems of the life cycle of the product, as well as reviewing the sources of emissions.

Due to the limitation of the database, some elementary 
streams do not have a well-defined production process and therefore are bases of supply chains. An example of these entries is diesel. Flows of this type are only consumed in processes.

Considering the operation of the simulator and the limitations of the database, an assessment of all materials used in the plant was done in order to make the data fit the software. These data are significant for calculations and comparisons of the life cycle of biodiesel. The set of data presented in Table 1 and Table 2 stand for the reagent consumption and production of a given compound per kilogram of biodiesel produced.

Table 1. Process Global Mass Balance - Inlet (Author, 2014).

\begin{tabular}{ll}
\hline Compound & Quantity (For kg of biodiesel Produced) \\
\hline Soy Oil $(\mathrm{kg})$ & 0,995429 \\
Methanol $(\mathrm{kg})$ & 0,121584 \\
Sodium Methoxide $(\mathrm{kg})$ & 0,011681 \\
Water $(\mathrm{kg})$ & 1,905231 \\
Fuel (heating) & 0,06427 \\
Electricity & 0,128702 \\
\hline
\end{tabular}

Table 2. Process Global Mass Balance - Outlet (Author, 2014).

\begin{tabular}{ll}
\hline Compound & Quantity (per kg of biodiesel Produced) \\
\hline Fatty acids & 0,002065 \\
Glycerin $(\mathrm{kg})$ & 0,105028 \\
\hline
\end{tabular}

Notes:

1) In Brazil the main heating fuel used in industries is natural gas (methane). The quantity in the table was calculated using the specific heat capacity of methane.

2) Based on the data from United Soybean Board report "Life Cycle Impact of Soybean Production and Soy Industrial Products"'[10]

3) Calculated from the excess soy oil that did not react.
For the characterization of the process, some of the most significant data were collected by the simulation data in Table 3. The most important items are discussed in this section and sub-items will be compared for better understanding of the values obtained.

Table 3. Simulation Results (Author, 2014).

\begin{tabular}{lll}
\hline Impact Category & Unity & Total \\
\hline Global Warming & $\mathrm{Kg} \mathrm{CO} 2-\mathrm{Eq}$ & 0,08579 \\
Acidification & $\mathrm{Mol} \mathrm{H}+-\mathrm{Eq}$ & 0,00727 \\
Eutrophication & $\mathrm{kg} \mathrm{N}$ & $5,98159 \times 10^{-7}$ \\
Human Toxicity - Carcinogenic & $\mathrm{kg}$ benzene - Eq & $1,16200 \times 10^{-5}$ \\
Human Toxicity - non Carcinogenic & $\mathrm{kg}$ toluene - Eq & 0,11114 \\
Photochemical oxidation & $\mathrm{Kg} \mathrm{NOx}-\mathrm{Eq}$ & $1,34690 \times 10^{-5}$ \\
Human Toxicity - Breathing & $\mathrm{kg} \mathrm{PM} 2.5-\mathrm{Eq}$ & $3,45332 \times 10^{-5}$ \\
Ozone layer destruction & $\mathrm{kg} \mathrm{CFC}-11-\mathrm{Eq}$ & $2,98755 \times 10^{-14}$ \\
Eco toxicity & $\mathrm{kg} \mathrm{2,4-D-Eq}$ & 0,00323 \\
\hline
\end{tabular}

\subsection{Toxicity}

The final disposal of wash water that comes from biodiesel production subsystem and the exits of methanol recovery subsystem is one of the concerns that need attention. Although it has pollutants and toxic materials, they cannot be discriminated in the simulator due to lack of information regarding its quantities and frequency, and for this reason it is not possible to achieve a significant toxicity factor.

Methanol is harmful to human health, being responsible for one of the indices of toxicity. Besides the production of methanol, the other subsystems that affect the categories analyzed in this section are the natural gas production and transportation of material ((due to the fuel burn - methane and Diesel). The analysis of impact and comparison to the Diesel system, based on the software data is presented in Table 4.

Table 4. Toxicity Comparison (Author, 2014).

\begin{tabular}{|c|c|c|c|c|}
\hline Impact Category & Unit & Biodiesel & Diesel & Rate Diesel / Biodiesel \\
\hline Human Toxicity Carcinogenic & kg benzene - eq & $1,162 \times 10^{-5}$ & 0,74886 & 64445,78 \\
\hline Human Toxicity non carcinogenic & $\mathrm{kg}$ toluene $-\mathrm{eq}$ & 0,11114 & $1,787 \times 10^{-4}$ & 160810,68 \\
\hline Human Toxicity Breathing & $\mathrm{kg} \mathrm{pm} 2.5-\mathrm{eq}$ & $3,453 \times 10^{-5}$ & 0,01081 & 313,03 \\
\hline Eco toxicity & kg 2,4-d-eq & 0,00323 & 443,68 & 137363,20 \\
\hline
\end{tabular}

All Categories related toxicity are much more significant in the case of Diesel. This difference can be less significant if the compounds for the treatment of glycerol were included in the study.

\subsection{Global Warming and Photochemical Oxidation}

As discussed by some authors [11], [12] a major current environmental concern is the emission of gases responsible for global warming. In Brazil, the excessive use of Diesel is one of the factors responsible for this emission. For a better comparison of the results obtained, we also used the program to simulate this category of impact for Diesel.

It is interesting to note first, that the software used the generation of $\mathrm{CO} 2$ gas for the simulation of the global warming potential. But, the quantity of gases generated while burning the fuels depends on the amount of carbon present in the fuel. This means that, if the comparison were conducted for the entire life cycle, including the final disposal of the product, the results would change. As this study covers only the activities to the generation of the fuel, it was decided to use the same mass of products to better equalize the comparison.

As you might expect, the biodiesel is less responsible for global warming than Diesel. This and other simulation results for the Diesel are shown and compared in Table 5. In the second and third columns, the table presents the results for the impact categories. The fourth column is the ratio between the result obtained by the Diesel and biodiesel.

Table 5. Global Warming: Diesel and Biodiesel Comparison (Author, 2014).

\begin{tabular}{|c|c|c|c|}
\hline \multicolumn{4}{|c|}{ Global Warming } \\
\hline Unit & Biodiesel & Diesel & Rate Diesel/Biodiesel \\
\hline $\mathrm{Kg} \mathrm{CO} 2-\mathrm{Eq}$ & 0,08579 & 14,916331 & 173,8703 \\
\hline
\end{tabular}


In some published studies [11], [12], the result of global warming for the production of biodiesel has a negative value. The reduction of global warming in these cases can be accounted to the use of raw material clean and renewable, which completes the cycle of carbon dioxide. This fact, however, is not consistent with the reality of the case study, since the diesel itself is used to transport cargo throughout the lifecycle of the product.

Another pertinent data obtained from the simulation of Diesel is the amount of nitrogenous gases generated in its production. The simulation results are shown in Table 6 .

Table 6. Photochemical Oxidation: Diesel and Biodiesel Comparison (Author, 2014).

\begin{tabular}{llll}
\hline \multicolumn{3}{l}{ Photochemical Oxidation } & \\
\hline Unit & Biodiesel & Diesel & Rate Diesel/Biodiesel \\
\hline $\mathrm{Kg} \mathrm{NOx}-\mathrm{Eq}$ & $1,34690 \times 10^{-5}$ & 0,36295 & 26512,05259 \\
\hline
\end{tabular}

One of the disadvantages of using biodiesel as fuel is generating NOx responsible for photochemical oxidation. However, by simulation, the production of biodiesel showed well below those of Diesel outcome. It can be inferred, therefore, that a great amount of the nitrogen absorbed by soybean goes through the stages of production and is only oxidized during fuel combustion.

To check which of the two fuels has the greatest potential for photochemical oxidation, the average mass of NOX resulted from the combustion of one kilogram of biodiesel was calculated. This calculation is based on data from [13]-[15] presented in Table 7.

Table 7. Percentage of Nitrogen in oil under study [13]-[15].

\begin{tabular}{llll}
\hline Acid & Molecular formula & \% Molar (N2) & Ratio C:N \\
\hline Palmitic & $\mathrm{C} 16 \mathrm{H} 32 \mathrm{O} 2$ & 11 & $16: 0$ \\
Stearic & $\mathrm{C} 18 \mathrm{H} 35 \mathrm{O} 2$ & 4 & $18: 0$ \\
Oleic & $\mathrm{C} 18 \mathrm{H} 34 \mathrm{O} 2$ & 23 & $18: 1$ \\
Linoleic & $\mathrm{C} 18 \mathrm{H} 32 \mathrm{O} 2$ & 54 & $18: 2$ \\
Linolenic & $\mathrm{C} 18 \mathrm{H} 30 \mathrm{O} 2$ & 8 & $18: 3$ \\
\hline
\end{tabular}

The average ratio between the number of atoms of carbon and nitrogen available is 18 atoms of carbon for 1.55 atoms of Nitrogen. Thus, 1.55 moles of nitrogen present in the oil can generate up to $0.244 \mathrm{~kg}$ of nitrogen oxides per kilogram of biodiesel burned. This value is very close to that simulated for Diesel (assuming here that the burning of Diesel does not generate nitrogen compounds). This means that the generation NOx cannot be considered a disadvantage of burning biodiesel, since Diesel production also produces similar quantities of the gas.

\section{Conclusion}

This study investigated the environmental impacts related to the life cycle of biodiesel from data extracted from a theoretical plant. There are two aspects that led to the interest in this research: first, the growing environmental concern; Second, the strategic position of Brazil in relation to biofuels production.

Although the inventory was based on the Brazilian reality, there is still not a consolidated basis of Brazilian data for the simulation. The use of the American base, however, does not affect the study, because this is only an estimate of a theoretical plant.

After extensive research on literature review, case study and representative process flows for construction of inventories were defined. For the simulation, we used free software, already with intent to disseminate research in this area.

Besides the simulation of the plant, was used as a baseline feature, the simulation of the impact related to the life cycle of Diesel. This comparison brought important results for this study. It was estimated that the production of biodiesel generates about 174 times less gas $\mathrm{CO}_{2}$, compared to the production of Diesel. It was also possible to see that both biodiesel and Diesel are responsible for $\mathrm{NO}_{\mathrm{X}}$ gases emissions and the environmental impact generated by these emissions is similar to the two fuels.

\section{References}

[1] R. Brecha, "Ten Reasons to Take Peak Oil Seriously," Sustainability, vol. 5, no. 2, pp. 664-694, Feb. 2013.

[2] M. A. Oehlschlaeger, "Prospects for Biofuels: A Review," $J$. Therm. Sci. Eng. Appl., vol. 5, no. 2, p. 021006, May 2013.

[3] S. Liu, H. Jia, B. Yin, Z. Xu, and T. Guan, "Investigation on Combustion Characteristics of Direct Injection Nature Inhale Diesel Engine Fuelled with Biodiesel," 2009 AsiaPacific Power Energy Eng. Conf., vol. 2, pp. 38-41, 2010.

[4] A. Holma, K. Koponen, R. Antikainen, L. Lardon, P. Leskinen, and P. Roux, "Current limits of life cycle assessment framework in evaluating environmental sustainability - case of two evolving biofuel technologies," J. Clean. Prod., vol. 54, pp. 215-228, Sep. 2013.

[5] ISO, ISO 14001 - Environmental Management Systems Specification with Guidance for Use. Geneva, Switzerland.: International Organization for Standardization, 1996.

[6] ISO, ISO 14040 International Standard. Environmental management - Life cycle assessment - Principles and framework. Geneva, Switzerland.: International Organisation for Standardization, 2006.

[7] ISO, ISO 14.044:2006. Geneva, Switzerland: International Organisation for Standardization, 2006.

[8] GreenDelta GmbH, “openLCA.” GreenDelta GmbH, Berlin, Germany, 2014.

[9] P. Sieira, E. B. F. Galante, W. A. Gonzales, and A. Haddad, "Life cycle inventory of a biodiesel production unit in Brazil," Am. J. Chem. Eng., vol. 2, no. 1, pp. 1-7, 2014.

[10] Omni Tech International, "Life Cycle Impact of Soybean Production and Soy Industrial Products," Washington, USA, 2010.

[11] C. M. Piekarski, L. Mendes, L. Zocche, and A. C. De Francisco, "Revista Gestão Industrial MÉTODOS DE AVALIAÇÃO DE IMPACTOS DO CICLO DE VIDA: ESPECIFICIDADES BRASILEIRAS LIFE CYCLE IMPACT ASSESSMENT METHODS : A DISCUSSION OF METHODS ADOPTION IN BRAZILIAN SPECIFITIES,”pp. 222-240, 2012. 
[12] S. Pinzi, D. Leiva, I. López-García, M. D. Redel-Macías, and M. P. Dorado, "Latest trends in feedstocks for biodiesel production," Biofuels, Bioprod. Biorefining, p. n/a-n/a, Aug. 2013.

[13] K. A. Costa, “A UTILIZAÇÃO DA AVALIAÇÃO DO CICLO DE VIDA NO PROCESSO DE TOMADA DE DECISÃO EM SUSTENTABILIDADE NA INDÚSTRIA DA CONSTRUÇÃO NO SUBSETOR DE EDIFICAÇÕES," UFF, 2012.
[14] R. A. B. Costa, "ESTUDO DAS EFICIÊNCIAS DE OPERAÇÃO E CONSUMO DE,” 2009.

[15] M. Hajbabaei, K. C. Johnson, R. A. Okamoto, A. Mitchell, M. Pullman, and T. D. Durbin, "Evaluation of the impacts of biodiesel and second generation biofuels on $\mathrm{NO}(\mathrm{x})$ emissions for CARB diesel fuels.," Environ. Sci. Technol., vol. 46, no. 16, pp. 9163-73, Aug. 2012. 